\title{
Role of Soy Isoflavones in Treatment Premenstrual Tension Syndrome Symptoms
}

G.A.El kholy, M.A.Mohamed, M.A.El Nory and A.A.El Halim

Obstetrics and Gynecology Dept., Faculty of Medicine, Benha Univ., Benha, Egypt

E-Mail:Amira125@Gmail.Com

\section{Abstract}

Nowadays, women's health is taken into account as one of their obvious rights and one of the main goals of social and economic development of societies; therefore, paying attention to problems and diseases that threaten women's physical and mental health, For example, such that premenstrual syndrome (PMS), is Around wellbeing necessities. The point about this Look into might have been will ponder the impact from claiming soy isoflavones ahead indications of premenstrual pressure syndrome. This may be a prospective, randomized, regulated investigation which incorporates (200) ladies whining about indications of premenstrual pressure syndrome around the individuals going to the outpatient gynecology facility of Benha school clinic. Our effects indicates that there will be huge Contrast the middle of those two aggregations Concerning illustration views behavioral transforms side effects ( $p$ esteem <0. 001). Our effects indicates that there will be critical distinction between those two bunches Likewise respects torment side effects ( $p$ esteem <0. 001). Our effects demonstrated that soy isoflavones enhances perimenstrual indications. Soy isoflavones Might a chance to be a standout amongst those dietary elements identified with those unpredictability for premenstrual syndrome (PMS).

Keywords: Isoflavones, PMS, Women's, Prospective and Behavioral.

\section{Introduction}

Nowadays, women's wellbeing will be made under record Concerning illustration a standout amongst their self-evident privileges What's more a standout amongst those principle objectives for social Also investment advancement from claiming social orders; therefore, giving careful consideration to issues Also illnesses that undermine women's physical and mental health, for example, such that premenstrual syndrome (PMS), will be Around wellbeing necessities [1].

Practically ladies of regenerative cell period might feel that's only the tip of the iceberg physiological or enthusiastic uneasiness in the week When the menses. These side effects camwood differ between people and bring those possibility to influence work, individual life, What's more spot extra anxiety around a relationship [2]. To all, 30\%-40\% from claiming ladies from claiming regenerative cell agdistis middle of the road from the a greater amount extreme PMS Also $3 \%-8 \%$ middle of the road from premenstrual dysphoric jumble (PMDD), which is the that's only the tip of the iceberg genuine variant for PMS [3].

The correct etiology of PMS may be unknown, At it might a chance to be identified with hormone varieties. A percentage hypotheses state that PMS may be not initiated Eventually Tom's perusing abnormal centralization for gonadal steroids Anyhow less averse Eventually Tom's perusing varieties over levels of the sex hormones. Those contrasts the middle of ladies for Furthermore without PMS might additionally make clarified Toward expanded affectability on varieties clinched alongside levels about sex hormones. Moreover, exactly investigations indicated that the onset Also course about PMS are identified with stress [4].

Those varieties Previously, hormone levels over the menstrual cycle make a expansion Previously, negative feelings clinched alongside ladies and might impact temperament regulation Furthermore affectability should stress [5].

\section{Subjects and methods}

This might have been An prospective, randomized, regulated investigation which included (200) ladies whining about indications of premenstrual pressure syndrome around the individuals going to the outpatient gynecology facility from claiming Benha college doctor's facility.

Randomization: Patients were booked haphazardly under two rise to bunches (each included 100 women); consider gathering and control group, the initial 100 tolerant might have been those contemplate assembly and the second 100 tolerant might have been the control assembly.

\section{1. Methodology}

The precipitants were chose as stated by these criteria. Incorporation criteria: period 17-35 years, vicinity from claiming PMS symptoms, general menstrual cycles (21-35 days) and no oral conceptive pill use to 4 weeks in the recent past investigation entry; no simultaneous help to PMS, including antidepressants, herbs Furthermore supplements, to 4 weeks When ponder entrance What's more give composed or verbal educated assent.

Prohibition criteria: unfavorable susceptibility to soybean alternately soybean products, vicinity from claiming neuropsychiatric issue and not kidding hepatic disease, heart disease, kidney sickness or threatening infection.

The moos menstrual trouble questionnaire (mdq) might have been used to assess premenstrual Furthermore menstrual side effects (moos, 1968) (appendix 1) premenstrual self - rating scale made by (Steiner et al, 1980) (appendix 2) afterward it might have been translated on arabic dialect (appendix 3) those questionnaire test comprised from claiming 5 particular information inquiries Also 43 things identified with the premenstrual side effects afterward those members were required will review those seriousness from claiming side effects after information gathering from patients those 
manifestations were assembled under eight sub aggregations arousal, water retention, concentration, negative affect, behavioral changes, pains, autonomic responses Also control.

These were completed after bringing history starting with tolerant for stress once :. 1-personal history: Name, age, sex, occupation Furthermore residence, conjugal state, parity, extraordinary propensities about restorative essentialness (smoking, alcohol, addiction, exercise Also r schedule, salt intake, sugar fruit intake, tea sack Also coffee).

2-Obstetric history: Gravidity, agdistis of principal full term delivery, premature births (number, date spontaneous or induced, habitual or sporadic), conveyances (number and span from claiming each, breast issues Throughout pregnancy, temperament for delivery, number for kids existing Furthermore died), At whatever difficulties (hypertension with pregnancy, extreme postpartum discharge requiring blood transfusion) What's more breast issues after conveyance alternately Throughout pregnancy.

3-Menstrual history: period for menarche (normal 919 years) punctual alternately late, normality of cycle: span from claiming period, sum of blood, Intermenstrual abdominal pain, Intermenstrual discharge, Intermenstrual spotting, Dysmenorrheal kind (primary - secondary), Intermenstrualmastalgia (cyclic alternately non-cyclic, spontaneous or looking into touch, what build the ache Furthermore the thing that decline the pain), date of the To begin with day of the last menstrual time and all premenstrual manifestations (edema, weight gain, change from claiming sexual desire, temperament changes, increment crying, social withdrawal Furthermore modified Every day activities).

4-Contraceptive historical backdrop. 5-past historical backdrop. 6-Family history. 7-present historical backdrop. All examination. Abdominal examination. Pelvic examination: will avoid later pelvic examination. Sonography: on avoid vicinity for pelvic pathology. The sum situations replied those inquiries done Moos menstrual trouble Questionnaire preceding beginning treatment, et cetera half those situations (study group) gained medication (soy isoflavones (Rosafem ends 5gm) holding $0.8 \mathrm{gm}$ soybeans twice Every day two weeks in the recent past menses to 3 cycles after that they replied the inquiries for Moos menstrual trouble Questionnaire that point took rest for 3 months At that point fill the Questionnaire once more.

The in turn half(the control group) gained placebo tablets in the type for chocolate ends rich for calcium, magnesium \&vitamin D3 (NutriMero)( Likewise these tablets required the same shape, span What's more flavor Similarly as soy isoflavones tablets) Double Every day two weeks preceding menses to 3 cycles then afterward that they replied those inquiries to Moos menstrual trouble Questionnaire that point took rest to 3 months then loaded the Questionnaire once more.

Information oversaw economy. Those clinical information were recorded around a report card manifestation. These information were tabulated and investigated utilizing the PC program SPSS (Statistical bundle for social science) rendition 20 .

\section{Results}

This table shows comparison between the study group and control group according to symptoms of PMS (arousal symptoms) before starting treatment, after 3 months of treatment and after rest of 3 months with highly significant difference between two groups Table (1).

This table shows comparison between the study group and control group according to symptoms of PMS (water retention symptoms) before starting treatment with significant difference between two groups, after 3 months of treatment and after rest of 3 months with highly significant difference between two groups and also shows comparison between results in study group (before starting treatment, after 3 months of treatment and after 3 months of treatment) which are highly significant difference, while in control group are of insignificant difference Table (2).

Insignificant difference between two groups, after 3 months of treatment with significant difference between two groups and after rest of 3 months with highly significant difference between two groups and also shows comparison between results in study group (before starting treatment, after 3 months of treatment and after 3 months of treatment) which are highly significant difference, while in control group are the same Fig (1).

Insignificant difference between two groups, after 3 months of treatment and after rest of 3 months with highly significant difference between two groups and also shows comparison between results in study group (before starting treatment, after 3 months of treatment and after 3 months of treatment) which are highly significant difference, while in control group are the same Table (3).

Highly significant difference between two groups and also shows comparison between results in study group (before starting treatment, after 3 months of treatment and after 3 months of treatment) which are highly significant difference, while in control group are of insignificant difference Table (4).

Table (1) Comparison between the studied groups according to arousal symptoms.

\begin{tabular}{|c|c|c|c|c|}
\hline \multirow[t]{2}{*}{ Arousal } & Base line (100) & After 3months (100) & $\begin{array}{l}\text { After rest of } 3 \\
\text { months }(100)\end{array}$ & \multirow[t]{2}{*}{$P$ value } \\
\hline & No & No & & \\
\hline
\end{tabular}




\begin{tabular}{|c|c|c|c|c|c|c|c|c|}
\hline \multicolumn{9}{|l|}{ Case group } \\
\hline & No & 42 & 42.0 & 96 & 96.0 & 84 & 84.0 & $<0.001 * *$ \\
\hline & Mild & 30 & 30.0 & 0 & 0.0 & 2 & 2.0 & \\
\hline & Moderate & 22 & 22.0 & 2 & 2.0 & 12 & 12.0 & \\
\hline & Severe & 6 & 6.0 & 2 & 2.0 & 2 & 2.0 & \\
\hline \multicolumn{9}{|c|}{ Control group } \\
\hline & No & 18 & 18.0 & 64 & 64.0 & 40 & 40.0 & $<0.001 * *$ \\
\hline & Mild & 38 & 38.0 & 24 & 24.0 & 36 & 36.0 & \\
\hline & Moderate & 32 & 32.0 & 8 & 8.0 & 18 & 18.0 & \\
\hline & Severe & 12 & 12.0 & 4 & 4.0 & 6 & 6.0 & \\
\hline $\mathbf{X}^{2}$ test & & \multicolumn{2}{|c|}{14.39} & \multicolumn{2}{|c|}{$\mathrm{FET}=40.2$} & \multicolumn{2}{|c|}{$\mathrm{FET}=54.39$} & \\
\hline$P$ value & & \multicolumn{2}{|c|}{$0.002 * *$} & \multicolumn{2}{|c|}{$<0.001 * *$} & \multicolumn{2}{|c|}{$<0.001 * *$} & \\
\hline
\end{tabular}

Table (2) Comparison between the studied groups according to water retention symptoms.

\begin{tabular}{|c|c|c|c|c|c|c|c|c|}
\hline \multirow[t]{2}{*}{ Water retention } & & \multicolumn{2}{|c|}{$\begin{array}{c}\text { Base line } \\
\text { (100) }\end{array}$} & \multicolumn{2}{|c|}{ After 3months (100) } & \multicolumn{2}{|c|}{$\begin{array}{l}\text { After rest of } 3 \\
\text { months (100) }\end{array}$} & \multirow[t]{2}{*}{$P$ value } \\
\hline & & No & $\%$ & No & $\%$ & $\mathrm{No}$ & $\%$ & \\
\hline \multicolumn{9}{|l|}{ Case group } \\
\hline & No & 28 & 28.0 & 80 & 80.0 & 72 & 72.0 & $<0.001 * *$ \\
\hline & Mild & 14 & 14.0 & 12 & 12.0 & 14 & 14.0 & \\
\hline & Moderate & 44 & 44.0 & 8 & 8.0 & 14 & 14.0 & \\
\hline & Severe & 14 & 14.0 & 0 & 0.0 & 0 & 0.0 & \\
\hline \multicolumn{9}{|l|}{ Control group } \\
\hline & No & 16 & 16.0 & 20 & 20.0 & 20 & 20.0 & 0.99 \\
\hline & Mild & 18 & 18.0 & 18 & 18.0 & 18 & 18.0 & \\
\hline & Moderate & 60 & 60.0 & 56 & 56.0 & 56 & 56.0 & \\
\hline & Severe & 6 & 6.0 & 6 & 6.0 & 6 & 6.0 & \\
\hline $\mathbf{X}^{2}$ test & & \multicolumn{2}{|c|}{9.43} & \multicolumn{2}{|c|}{$\mathrm{FET}=85.06$} & \multicolumn{2}{|c|}{$\mathrm{FET}=63.95$} & \\
\hline P value & & \multicolumn{2}{|c|}{$0.024 *$} & \multicolumn{2}{|c|}{$<0.001 * *$} & \multicolumn{2}{|c|}{$<0.001 * *$} & \\
\hline
\end{tabular}

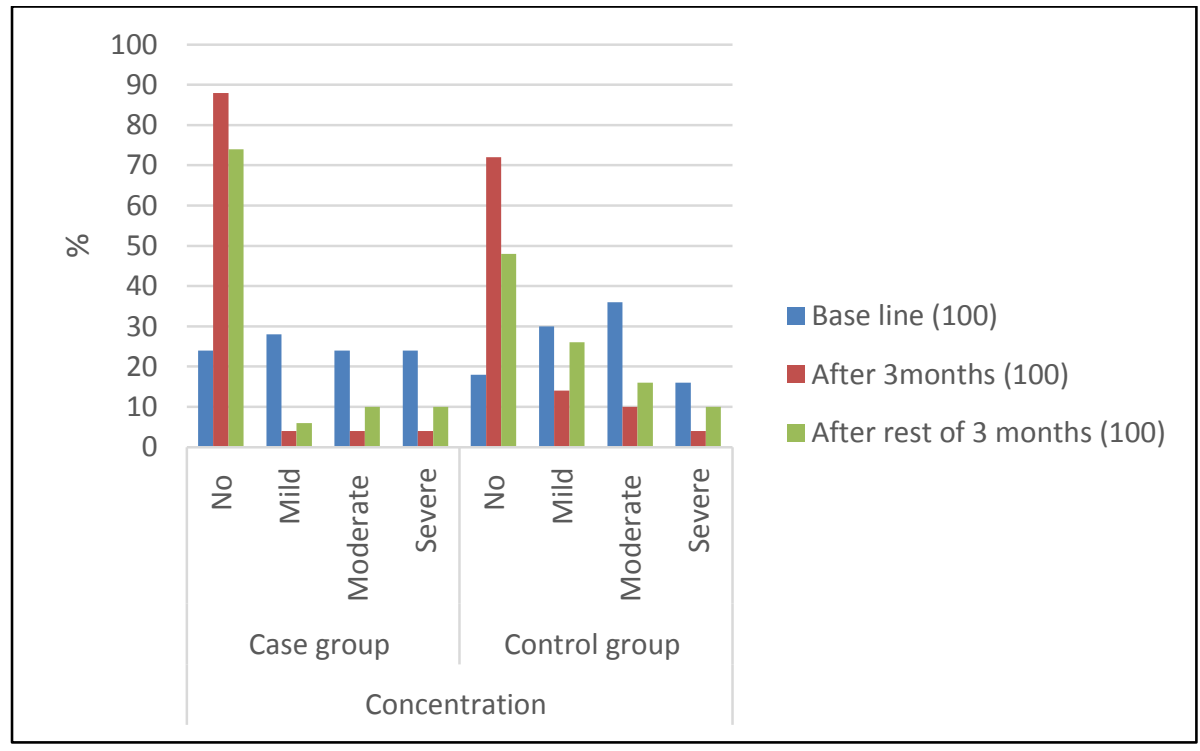

Fig (1) Comparison between the studied groups according to Concentration symptoms.

Table (3) Comparison between the studied groups according to negative affect symptoms.

\begin{tabular}{|c|c|c|c|c|c|c|c|c|}
\hline \multirow[t]{2}{*}{ Negative affect } & & \multicolumn{2}{|c|}{ Base line (100) } & \multicolumn{2}{|c|}{ After 3months (100) } & \multicolumn{2}{|c|}{$\begin{array}{l}\text { After rest of } 3 \text { months } \\
(100)\end{array}$} & \multirow[t]{2}{*}{$P$ value } \\
\hline & & No & $\%$ & No & $\%$ & No & $\%$ & \\
\hline \multicolumn{9}{|l|}{ Case group } \\
\hline & No & 20 & 20.0 & 92 & 92.0 & 82 & 82.0 & $<0.001 * *$ \\
\hline
\end{tabular}




\begin{tabular}{|c|c|c|c|c|c|c|c|c|}
\hline & Mild & 34 & 34.0 & 4 & 4.0 & 10 & 10.0 & \\
\hline & Moderate & 32 & 32.0 & 4 & 4.0 & 6 & 6.0 & \\
\hline & Severe & 14 & 14.0 & 0 & 0.0 & 2 & 2.0 & \\
\hline \multicolumn{9}{|c|}{ Control group } \\
\hline & No & 16 & 16.0 & 70 & 70.0 & 44 & 44.0 & $<0.001 * *$ \\
\hline & Mild & 28 & 28.0 & 16 & 16.0 & 22 & 22.0 & \\
\hline & Moderate & 44 & 44.0 & 12 & 12.0 & 26 & 26.0 & \\
\hline & Severe & 12 & 12.0 & 2 & 2.0 & 8 & 8.0 & \\
\hline $\mathbf{X}^{2}$ test & & \multicolumn{2}{|c|}{3.07} & \multicolumn{2}{|c|}{$\mathrm{FET}=15.86$} & \multicolumn{2}{|c|}{32.06} & \\
\hline$P$ value & & \multicolumn{2}{|c|}{0.38} & \multicolumn{2}{|c|}{$0.001 * *$} & \multicolumn{2}{|c|}{$<0.001 * *$} & \\
\hline
\end{tabular}

Table (4) Comparison between the studied groups according to Pains symptoms .

\begin{tabular}{|c|c|c|c|c|c|c|c|c|}
\hline \multirow[t]{2}{*}{ Pain } & & \multicolumn{2}{|c|}{ Base line (100) } & \multicolumn{2}{|c|}{ After 3months (100) } & \multicolumn{2}{|c|}{$\begin{array}{l}\text { After rest of } 3 \text { months } \\
(100)\end{array}$} & \multirow[t]{2}{*}{ P value } \\
\hline & & No & $\%$ & No & $\%$ & $\mathrm{No}$ & $\%$ & \\
\hline \multicolumn{9}{|c|}{ Case group } \\
\hline & No & 12 & 12.0 & 80 & 80.0 & 62 & 62.0 & $<0.001 * *$ \\
\hline & Mild & 14 & 14.0 & 8 & 8.0 & 8 & 8.0 & \\
\hline & Moderate & 38 & 38.0 & 8 & 8.0 & 18 & 18.0 & \\
\hline & Severe & 36 & 36.0 & 4 & 4.0 & 12 & 12.0 & \\
\hline \multicolumn{9}{|c|}{ Control group } \\
\hline & No & 18 & 18.0 & 18 & 18.0 & 18 & 18.0 & 1.0 \\
\hline & Mild & 34 & 34.0 & 36 & 36.0 & 34 & 34.0 & \\
\hline & Moderate & 34 & 34.0 & 32 & 32.0 & 34 & 34.0 & \\
\hline & Severe & 14 & 14.0 & 14 & 14.0 & 14 & 14.0 & \\
\hline $\mathbf{X}^{2}$ test & & \multicolumn{2}{|c|}{19.44} & \multicolumn{2}{|c|}{77.0} & \multicolumn{2}{|c|}{45.37} & \\
\hline$P$ value & & \multicolumn{2}{|c|}{$<0.001 * *$} & \multicolumn{2}{|c|}{$<0.001 * *$} & \multicolumn{2}{|c|}{$<0.001 * *$} & \\
\hline
\end{tabular}

\section{Discussion}

Premenstrual manifestations happen done $95 \%$ for know ladies for regenerative cell age, with $5 \%$ for the individuals ladies anguish starting with PMS [6].

An eating regimen rich clinched alongside grains, vegetables, fruits, vitamins What's more minerals need been supported. Restricted admission complex from claiming fat, salt Also caffeine-containing refreshments need been proposed. However, those proofs supporting such proposals need been ambiguous. Dietary change Similarly as An medication for PMS need included proposals for nourishments rich Previously, grains, vegetables, vitamins, Also minerals Anyway low On fat, sodium, caffeine, What's more liquor [6] suggester the principle point of a dietary progress will be to decrease circle estrogen and on piece its connection to receptor sites, and additionally should increment serotonin amalgamation.

Isoflavones need aid An population of phytoestrogens found predominantly over legumes

What's more beans. Soybeans need aid An rich sourball from claiming isoflavones [7]. Isoflavones could make found On exactly 300 plants, Anyhow are especially abundant On soy.

The introduce examine demonstrates correlation the middle of the contemplate aggregation What's more control bunch as stated by indications of PMS (arousal symptoms) When beginning treatment, then afterward 3 months about medication What's more then afterward rest of 3 months for Exceptionally critical Contrast between two gatherings.

A large number investigations didn't incorporate arousal indications Previously, their investigation done MDQ score in light of it's was troublesome on evaluate arousal indications. However, Previously, [3] examine which might have been should analyze the impacts of isoflavone and Cynanchumwilfordii to change from claiming premenstrual syndrome, dysmenorrhea in 30 school ladies Furthermore accounted for that there's a critical diminish to arousal manifestations then afterward soy admission complex.

Our comes about accounted for a examination between those contemplate bunch Also control aggregation as stated by indications of PMS (water maintenance symptoms) in front of beginning medicine with huge distinction between two groups, following 3 months of medicine and after $r$ from claiming 3 months with Exceedingly noteworthy Contrast the middle of two bunches and also reveals to correlation the middle of brings about investigation gathering (before beginning treatment, after 3 months from claiming medicine Furthermore after 3 months of treatment) which need aid Exceptionally critical Contrast, same time to control aggregation are of inconsequential distinction.

Those same outcomes attained by [3] examine who accounted for a Exceedingly noteworthy Contrast following soy isoflavones admission complex Toward 8 week. Which will be An cross-sectional ponder. Those example might have been produced dependent upon of 84 korean ladies existing in the USA, age-old 
28-40 A long time. Those Moos menstrual trouble Questionnaire (MDQ) and the nourishment recurrence Questionnaire were utilized Likewise estimation instruments.

This consider indicates no statically Contrast then afterward soy admission complex Disregarding inaccessibility those soy isoflavone admission complex might have been essentially associated with downright MDQ scores in the menstrual stage. In the exhibit study we indicated a correlation between the ponder gathering What's more control assembly as stated by indications of PMS (concentration symptoms) When beginning medication with inconsequential distinction between two groups, following 3 months of medicine for noteworthy Contrast between two bunches and then afterward rest for 3 months with profoundly huge Contrast the middle of two gatherings What's more likewise reveals to examination between brings about consider gathering (before beginning treatment, following 3 months for medicine and after 3 months of treatment) which would Exceptionally critical Contrast, same time for control assembly are the same.

As stated by negative influence symptoms, our examine indicated examination the middle of the ponder one assembly and control assembly as stated by indications of PMS (negative influence symptoms) in front of beginning medicine for inconsequential distinction between two groups, following 3 months for medicine Also then afterward rest from claiming 3 months with profoundly critical distinction the middle of two aggregations Also Additionally indicates correlation the middle of brings about investigation aggregation (before beginning treatment, following 3 months of medicine Furthermore after 3 months about treatment) which would Exceptionally huge Contrast, same time On control gathering are those same.

As stated by [3], negative influence manifestations will be diminished with soy admission complex in substantial dosage admission complex. It implies that there's a statically huge change over negative influence manifestations with soy Be that compelling reason a bigger measurements over other indications.

Over our investigation, An examination between the investigation one assembly Furthermore control assembly as stated by indications of PMS (Behavioral transforms symptoms) might have been completed in front of beginning medication for inconsequential distinction the middle of two groups, after 3 months of medicine Also then afterward rest about 3 months with profoundly critical distinction the middle of two aggregations Furthermore Additionally reveals to examination the middle of brings about examine aggregation (before beginning treatment, then afterward 3 months from claiming medication and following 3 months for treatment) which would profoundly

noteworthy difference, same time to control one assembly need aid those same.

Past studies' comes about fluctuate over the impact from claiming soy admission complex to diminishing agony. In the same transport for our come about is investigations same time [3] study dosn'tFit for for our comes about.

\section{Conclusion}

our results suggest that soy isoflavones improves mainly mild perimenstrual symptoms. soy isoflavones could be one of the dietary factors related to the complexity of premenstrual syndrome (PMS).

\section{References}

[1] KC. Olson, HA. Carroll, MK. Lustyk,Psychophysiological stress reactivity relationships across the menstrual cycle. J Horm; Vol.6, PP.1-5, 2015.

[2] ST. Sigmon, JG. Schartel, BA. Herman, The relationship between premenstrual distress and anxiety sensitivity: the mediating role of rumination. J Rat Emo Cognitive BehavTher; Vol.27, PP.188-200, 2009.

[3] A. Ryu, TH. Kim, Premenstrual syndrome: a mini review. Maturitas; Vol.82(4), PP.436-440, 2015.

[4] KA. Yonkers, PMS. O’Brien, E. Eriksson, Premenstrual syndrome. Lancet;Vol.371(9619),PP.1200-1210, 2008.

[5] L. Ossewaarde, GA. van Wingen, M. Ripkema, Menstrual cycle-related changes in amygdale morphology are associated with changes in stress sensitivity. Hum Brain Mapp; Vol.34(5), PP.1187$1193,2013$.

[6] Z. Jing, X. Yang, KM. Ismail, Chinese herbal medicine for premenstrual syndrome. Cochrane Database Syst Rev;Vol.1(006414), 2011.

[7] A. Vincent, LA. Fitzpatrick, Soy isoflavones: are they useful in menopause?. Mayo Clin. Proc; Vol.75, PP.1174-1184, 2010. 